\title{
ETNOPOÉTICA DO OLHAR
}

Gilmar Rocha*

\section{Resumo}

Antes de ser um fato jurídico, língüístico ou político, o estrangeiro é uma narrativa sobre a diferença produzida pelo olhar, cuja principal característica está em revelar um sistema de significados sociais. A música $O$ estrangeiro, de Caetano Veloso, propõe um exercício de reflexão conduzido por um "olhar antropológico", isto é, por um processo de transformação do familiar em exótico e do exótico em familiar, sobre o significado do estrangeiro no contexto da pósmodernidade.

Palavras-chave: Estrangeiro, olhar antropológico, pós-modernidade.

\section{Quem sou eu?}

O estrangeiro, composição de Caetano Veloso (1989) desempenha um valor semelhante ao que Roberto DaMatta (1973) chama de "letra de referência": um texto deflagrador que serve de introdução a um imaginário capaz de revelar como os homens refletem sobre a sua própria realidade, bem como a um exercício de estranhamento quanto à significação dessas mesmas experiências sociais.

O ponto de partida é o da etnopoesia. Nela, o próprio texto ganha vida, torna-se referência não de uma realidade determinada strictu sensu, mas de um imaginário social. Cruzamento de outros textos, a etnopoesia é intertextual, "o resultado é", nas palavras de Bader, em introdução à Etnopoesia de Fichte (1987, p. 19),

* Professor do Núcleo de Antropologia, Departamento de Sociologia da PUCMinas.

E-mail: gil@pucminas.br 
na planura do texto geral como dentro de cada parte, uma composição aberta, não unívoca, surpreendente, múltipla, que dá ao leitor a liberdade de entrelaçar e ligar: partículas da realidade são constantemente desfeitas e associativamente combinadas, lugares, pessoas e épocas são montados diretamente lado a lado, percepções do autor misturam-se a experiências autênticas dos protagonistas.

O texto de Caetano Veloso parece realizar a promessa da etnopoesia, na medida em que alia um aguçado "olhar antropológico" com uma "imaginação literária" na interpretação do estrangeiro. Conjugando o trabalho de análise dos dados etnográficos com um exercício de imaginação, a etnopoesia constitui-se numa forma de experimento em que antropologia e literatura se fundem, até certo ponto, no processo de conhecimento e construção da realidade social. ${ }^{1}$

$O$ estrangeiro, de Caetano Veloso, nos convida a um "olhar antropológico" sobre o fenômeno social do "outro" e, portanto, sobre o problema da diferença. Diferença essa que, à primeira vista, reside no "outro" mas que, de um outro ponto de vista, inscreve-se no "eu", pois a diferença está no olhar. Mas, vejamos o que o "etnopoeta" nos fala do estrangeiro:

O pintor Paul Gauguin amou a luz da Baía de Guanabara

O compositor Cole Porter adorou as luzes na noite dela

A Baía de Guanabara

O antropólogo Claude Lévi-Strauss detestou a Baía de Guanabara:

Pareceu-lhe uma boca banguela

E eu, menos a conhecera mais a amara?

Sou cego de tanto vê-la, de tanto tê-la estrela

O que é uma coisa bela?

O amor é cego

Ray Charles é cego

Stevie Wonder é cego

E o albino Hermeto não enxerga mesmo muito bem

Uma baleia, uma telenovela, um alaúde, um trem?

Uma arara?

Mas era ao mesmo tempo bela e banguela a Guanabara

Em que se passara passa passará o raro pesadelo 
Que aqui começo a construir sempre buscando o belo e o Amaro $\mathrm{O}$ amaro

Eu não sonhei:

A praia de Botafogo era uma esteira rolante de areia branca e óleo diesel

Sob meus tênis

E o Pão de Açúcar menos óbvio possível

À minha frente

Um Pão de Açúcar com umas arestas insuspeitadas

À áspera luz laranja contra a quase não-luz quase não púrpura

Do branco das areias e das espumas

Que era tudo quanto havia então de aurora.

Estão às minhas costas um velho de cabelos nas narinas

E uma menina ainda adolescente muito linda

Não olho pra trás mas sei de tudo

Cego às avessas, como nos sonhos, vejo o que desejo

Mas eu não desejo ver o terno negro do velho

Nem os dentes quase não púrpuras da menina

(Pense Seurat e pense impressionista

essa coisa de luz nos brancos dente e onda

mas não pense surrealista que é outra onda)

E ouço as vozes

Os dois me dizem

Num duplo som

Como que sampleados num Sinclavier:

"É chegada a hora da reeducação de alguém

Do Pai do Filho do Espírito Santo amém

O certo é louco tomar eletrochoque

O certo é saber que o certo é certo

O macho adulto branco sempre no comando

E o resto ao resto, o sexo é o corte, o sexo

Reconhecer o valor necessário do ato hipócrita

Riscar os índios, nada esperar dos pretos."

$\mathrm{E}$ eu, menos estrangeiro no lugar que no momento

Sigo mais sozinho caminhando contra o vento

E entendo o centro do que estão dizendo

Aquela cara e aquela:

É um desmascaro 
Singelo grito:

"O rei está nu".

Mas eu me desperto porque tudo cala frente ao fato de que o rei é mais bonito nu

E eu vou e amo o azul, o púrpura e o amarelo

E entre o meu ir e o sol, um aro, um elo.

("Some may like a soft Brazilian singer

But I've given up all attempts at perfection.")

Uma primeira leitura de $O$ estrangeiro sugere-nos de imediato um repertório de perguntas: quem são Paul Gauguin, Cole Porter e o antropólogo Claude Lévi-Strauss? Qual o significado da Baía de Guanabara? Qual o sentido das insistentes recorrências do autor ao olhar? Por que "o rei está nu"? Enfim, a pergunta principal que o autor se faz é: quem ou o que sou eu? Essas e muitas outras perguntas orientam nossa análise antropológica.

O objetivo é realizar uma interpretação do estrangeiro à luz de uma dupla transformação: de um lado, como processo de relativização do exótico em familiar e/ou do familiar em exótico; do outro lado, como parte de um processo mais amplo de mudança da imagem do estrangeiro como "outro" em direção à imagem do "eu”, estrangeiro. ${ }^{2}$

\section{O familiar e o exótico}

$O$ estrangeiro tem suscitado algumas interpretações significativas no que diz respeito a sua mensagem. Para os biógrafos Luchesi e Dieguez (1993, p. 202), o disco Estrangeiro,

longe de representar o abandono das raízes brasileiras, é reaproveitamento de uma palavra dita por Caetano no limiar do movimento tropicalista: [...] Quem sou eu? Sou $O$ rei da vela, de Oswald de Andrade, montado pelo Grupo Oficina. Sou brasileiro, sou casado e sou solteiro, sou baiano e estrangeiro...

Nesse caso, $O$ estrangeiro representa uma retomada das propostas firmadas pelo tropicalismo. Para Canevacci, em seu "brazileirante" Sincretismos: uma exploração das hibridações 
culturais, $O$ estrangeiro é uma crítica antropofágica, herdeira do modernismo oswaldiano dos anos 20 e do tropicalismo dos anos 70, aos "racionalismos incontaminados e refinados etnocentrismos" de LéviStrauss, uma vez que o antropólogo vê na Baía de Guanabara uma boca banguela. Ao passo que "um brasileiro comum pode interpretá-los carnalmente (e antropofagicamente) como seios morenos...", diz Canevacci (1996, p. 30). Não residiria nessa afirmação do autor também um quê de racionalismo e "exotismo" quando vê na Baía de Guanabara "seios morenos"?

Por outro lado, uma interpretação mais significativa nos é fornecida por Carvalho, numa perspectiva "desconstrucionista" na qual $O$ estrangeiro "pode ser considerado um texto de base dialética, em que a significação não está pronta, o que requer um leitor-ouvinte provocado a construí-la" (CARVALHO, 1993, p. 70). Também essa é nossa interpretação, cuja leitura, orientada por uma perspectiva antropológica, nos permite extrair do texto de Caetano Veloso outros sentidos que não aqueles construídos pelas leituras anteriores. Portanto, não é nosso propósito desenvolver aqui uma "análise do discurso" no sentido estrito da palavra, tão-somente realizar uma leitura interpretativa em que, do ponto de vista etnográfico, a música de Caetano Veloso nos sugere uma "atitude de estranhamento" embutida na poética do estrangeiro, como metáfora de um "olhar antropológico".

Tomando por modelo de análise a perspectiva aberta por Roberto DaMatta (1978) acerca do "trabalho de campo como um rito de passagem", é que procuramos ler e ver em $O$ estrangeiro um processo de transformação do familiar em exótico e do exótico em familiar. Sabese quão importantes são as viagens como fontes de mudança na perspectiva do olhar. Em particular, essa mudança de perspectiva será acentuada pela prática etnográfica do trabalho de campo. Desde o momento em que instituiu o trabalho de campo como uma exigência metodológica, a antropologia contribuiu para o enriquecimento do conhecimento das ciências sociais e humanas. De um lado, porque o trabalho de campo passou a contribuir para o próprio desenvolvimento e enriquecimento teórico da disciplina; do outro lado, como diz DaMatta (1978, p. 35), por ser este "o lado menos rotineiro e o mais difícil de ser apanhado da situação antropológica, é certamente porque ele se constitui 
no aspecto mais humano da nossa rotina". Ou seja, é a atividade capaz de permitir um maior aprofundamento na experiência de outros modos de vida, com valores diferentes do nosso, mas que, ao fim, enriquece nossa própria visão de mundo e acaba por nos trazer mais para dentro da nossa própria sociedade. Em outras palavras, se inicialmente o trabalho de campo nos leva para fora do nosso próprio mundo, posteriormente nos traz de volta mais para dentro dele. Nisso consiste a transformação do familiar em exótico e do exótico em familiar, desenvolvida pela prática etnográfica do trabalho de campo; ou seja, trata-se da possibilidade de reconhecer na cultura do "outro" formas diferenciadas de soluções para problemas comuns aos homens e, ao mesmo tempo, de descobrir, quando se olha para a própria cultura, um certo grau de cegueira ou miopia cultural por estarmos acostumados a naturalizar o social e o histórico a partir dos "pré-conceitos" e idéias etnocêntricas.

Se o modelo clássico do trabalho antropológico implica a realização de uma viagem cujo deslocamento se realiza no espaço, de uma cultura para outra, em que se busca transformar o exótico em familiar; outra é a possibilidade de uma viagem cujo deslocamento é vertical, a exemplo dos xamãs das sociedades primitivas que realizam uma "viagem sem sair do lugar", porém "para dentro" da própria cultura; nesse caso, a transformação é do familiar em exótico. Nessa, a dificuldade é, aparentemente, menor porque conhecemos o que está à nossa volta. $\mathrm{Na}$ verdade, só estamos familiarizados a elas. Portanto, a transformação do exótico em familiar nunca é mais fácil. Ao final do processo, uma transformação mais profunda atinge o saber e o olhar do antropólogo no que diz respeito à sua própria cultura e à cultura do outro.

Gilberto Velho (1978, p. 39), aprofundando a análise de DaMatta, sugere certas complicações quando nos adverte para o fato de que "o que sempre vemos e encontramos pode ser familiar mas não é necessariamente conhecido e o que não vemos e encontramos pode ser exótico mas, até certo ponto, conhecido". Aquilo que está próximo, na maioria das vezes, está embaçado pelos preconceitos, hábitos e estereótipos que formam a rotina do senso comum; ao contrário, aquilo que está distante, relativo a uma outra sociedade e cultura como, por exemplo, o american way of life, pode ser conhecido em decorrência da intensidade e frequiência com que é noticiado e representado pela televisão, cinema 
etc. Em particular, sociedades complexas como as metrópoles constituem um solo fértil e/ou campo privilegiado para experimentar essas transformações e complicações, por condensarem uma pluralidade de situações em função da grande heterogeneidade cultural e diversidade social, econômica, política, religiosa, estética etc. De resto, vale dizer, em época de globalização as relações entre o familiar e o exótico e o "eu" e o "outro" ganham um colorido especial e colocam o estrangeiro no centro das atenções.

Nessa perspectiva, $O$ estrangeiro ilustra de modo exemplar esse processo de transformação do exótico em familiar e do familiar em exótico, pois, estranhamente, aquilo que está distante (o exótico) muitas vezes está próximo (conhecido) e o que está próximo (familiar) pode estar distante (não conhecido). Basicamente, é quanto ao processo de transformação do familiar em exótico que $O$ estrangeiro chama a nossa atenção.

\section{"Eu”, estrangeiro}

O ponto a partir do qual se desenvolve e se posiciona o olhar estrangeiro é a Baía de Guanabara. Considerada um dos cartões postais do Brasil e, em particular, da cidade do Rio de Janeiro, a Baía de Guanabara desde o início teve sua imagem associada à visão do paraíso tropical. Já em 1516, encontramos uma das primeiras referências à Baía de Guanabara em A utopia, de Thomas Morus. Posteriormente, muitos outros viajantes que aportaram por essas bandas continuaram a acentuar sua beleza exuberante, contribuindo assim para que se formasse no início do século a imagem da Cidade Maravilhosa. Por exemplo, o francês Ferdinand Denis exaltava a beleza natural das terras brasileiras à vista da Baía dizendo tratar-se de um "país privilegiado". Também o alemão Rugendas (1989, p. 26-27), através de suas pinturas acentuaria a idéia de que

talvez não exista no mundo uma região como a do Rio de Janeiro, com paisagens e belezas tão variadas, tanto do ponto de vista da forma grandiosa das montanhas como dos contornos das praias. 
Caberia aos próprios brasileiros acentuar as belezas naturais do lugar em poesias, músicas, pinturas etc. Mas, sem dúvida, a principal homenagem prestada ao Rio de Janeiro e à Baía de Guanabara foi a construção do Cristo Redentor em 1931. Do alto do Corcovado, de braços abertos, ao mesmo tempo em que num gesto de "cordialidade" recebe a todos os estrangeiros, performaticamente simula uma integração cosmológica com a natureza abençoada; afinal de contas, "Deus é brasileiro".

Aos olhos dos artistas Gauguin e Cole Porter, a Baía de Guanabara é luz. Luz que ganha um colorido todo especial se vista da perspectiva impressionista das artes. De um lado, Gauguin, um dos expoentes do movimento impressionista da pintura francesa da segunda metade do século XIX, ama a luz da Baía de Guanabara; do outro lado, Cole Porter, compositor popular norte-americano de blues e jazz nos anos 30 , que não ficou imune à influência do impressionismo musical, adora as luzes na noite dela. Até aqui os estrangeiros, Gauguin e Porter, nos revelam o familiar, a Baía de Guanabara. No entanto, o antropólogo Claude LéviStrauss detestou a Baía de Guanabara, "pareceu-lhe uma boca banguela". Imagem encontrada em Tristes trópicos, em que o antropólogo diz:

Parece-me que a paisagem do Rio não está à escala das suas dimensões. O Pão de Açúcar e o Corcovado, todos esses locais tão gabados assemelham-se, para o viajante que entra na baía, a raízes de dentes perdidas nos quatro cantos duma boca desdentada. (LÉvISTRAUSS, 1979, p. 74)

Como se explica essa diferença de olhares? Somos levados a pensar o sentido do próprio olhar. ${ }^{4}$

Sob a suspeita de um "olhar antropológico", Lévi-Strauss lança luzes sobre o familiar. A dúvida se instaura quando logo em seguida é o compositor quem questiona: "E, eu, menos a conhecera, mais a amara? / Sou cego de tanto vê-la, de tanto tê-la estrela / O que é uma coisa bela?". Afinal, a Baía de Guanabara, luz adorada e amada, detestada porque parecida com uma boca banguela, é também o que menos se conhece e mais se ama, a estrela que ofusca a visão provocando cegueira. Bela. Mas o que é uma coisa bela? Como se vê, aqui o compositor nos induz a um processo de relativização que vai crescendo à medida 
que se avança na leitura da música. Nesse processo ocorre uma mudança no sentido do olhar ao mesmo tempo em que se modifica o significado do estrangeiro.

À maneira do antropólogo, também o "etnopoeta" aos poucos começa a estranhar a imagem "insuspeitada" da Baía de Guanabara. Os questionamentos do compositor põem em dúvida as certezas e, portanto, a cegueira de quem vê e não olha. Na medida em que Caetano Veloso vai assumindo uma atitude de estranhamento e de relativização diante desse "cartão postal", o significado do estrangeiro vai ganhando outro sentido, imposto por um olhar mais antropológico.

Em verdade, toda composição é significativamente marcada pelo sentido do olhar de estranhamento. Vejamos: "O amor é cego", diz o ditado popular, que também diz que o amor é belo. E o cego é capaz de ver belezas que não são vistas a "olho nu" por qualquer um. Ao passo que, na visão de muitos, o belo, tal como "uma baleia, uma telenovela, um alaúde, um trem? / uma arara?", pode representar uma certa miopia cultural. ${ }^{5}$ Sem negar a beleza da Baía de Guanabara, mas também sem desprezar o olhar crítico, pois "ao mesmo tempo era bela e banguela a Guanabara", opera-se uma transformação do "olhar estrangeiro". Da contraposição inicial entre arte e ciência, isto é, as visões dos artistas Paul Gauguin e Cole Porter em oposição à visão do cientista social, o antropólogo Claude Lévi-Strauss, aos poucos o estranhamento se apossa do olhar do "etnopoeta", num certo sentido, um misto de artista e cientista. Daí a referência à passagem ou mudança - quando o poeta diz: "Em que se passara passa passará o raro pesado / Que aqui começo a construir sempre buscando o belo e o amaro" - representar o processo de (des)construção do belo e do amargo. Trata-se de um processo dialético em que o belo e o amaro (amargo) são destruídos e recombinados para dar lugar a uma outra composição, a uma nova imagem. Por isso, de pronto, anuncia o poeta: "Eu não sonhei", pois é como se de repente levantasse "à minha frente / um Pão de Açúcar com umas arestas insuspeitadas. Um Pão de Açúcar menos óbvio possível", a praia de Botafogo de areias brancas e limpas cede lugar ao "óleo diesel" e tudo quanto havia então "do branco da areia e das espumas" é, talvez, somente um efeito de luz. "Cego às avessas... vejo o que desejo", isto porque "como nos sonhos" a realidade, até certo ponto, é imaginada. "Não olho 
para trás mas sei de tudo", reafirma a ilusão de que olhamos aquilo que vemos. Não deixa de ser significativo que "estão às minhas costas um velho de cabelos nas narinas / E uma menina ainda adolescente e muito linda" represente, conforme sugere Carvalho (1993), "a concepção de um mundo de valores sedimentados, onde as diferenças já estão instituídas e as verdades estabelecidas". Em outras palavras, estamos acostumados a ver no velho o feio, o negro, o passado. Por isso, quando diz: "Mas eu não desejo ver o terno negro do velho", o poeta propõe uma inversão do olhar que será pensada à luz do impressionismo. "Pense Seurat e pense impressionista". O impressionismo se caracteriza por uma nova maneira de olhar para a realidade e para a pintura, em que esta última é elevada ao status de realidade. 6

É nessa perspectiva que podemos entender a crítica do compositor logo em seguida, quando questiona a verdade e a realidade impostas pela tradição, pela ciência e pelo poder ocidental, referidas nos versos entre aspas: "É chegada a hora da reeducação de alguém... Riscar os índios nada esperar dos pretos". Reeducação do olhar que põe em dúvida a certeza das verdades preestabelecidas. É preciso, portanto, "reconhecer o valor necessário do ato hipócrita", o de que "o certo é louco tomar eletrochoque / o certo é saber que o certo é certo...". O ponto catártico da composição é, então, a descoberta: "E eu menos estrangeiro no lugar que no momento". O estrangeiro mais do que o resultado de uma distância espacial constitui-se uma distância social e/ ou psicológica provocada pelo momento, pelo tempo.

Sem sair do lugar, o estrangeiro nem sempre se encontra no "outro", mas sim no "eu”. Estrangeiro de si mesmo, acostumado que se está a ver e não olhar, a não estranhar o mundo que se habita, porque habita em mim um "outro", às vezes mascarado de um "eu". Em suma: "É um desmascaro / Singelo grito / 'O rei está nu' / Mas eu desperto porque tudo cala frente ao fato de que o rei é mais bonito nu”. É preciso, então, tirar as máscaras,

tirar a capa de membro de uma classe e de um grupo social específico para poder - como etnólogo - estranhar alguma regra social familiar e assim descobrir (ou recolocar, como fazem as crianças quando perguntam os "porquês") o exótico no que está petrificado dentro 
de nós pela reificação e pelos mecanismos de legitimação. (DaMatta, 1978, p. 28-29)

E mais: é preciso ousar olhar, despir os olhos da cegueira ou miopia cultural para, quem sabe assim, podermos ver o rei nu. É preciso, enfim, ilustra a fábula, ousar como a criança que viu a nudez do rei quando todos viam uma bela roupa invisível. ${ }^{7}$ Mesmo que tudo e todos se calem, o fato é que o rei é mais bonito nu. Sob a inspiração de uma estética impressionista, com outros olhos, o compositor pinta uma nova tela, um sistema como pensa Seurat, unindo o azul, o púrpura e o amarelo formando "entre o meu ir e o do sol um aro, um elo".

Por fim, Caetano lança mão de uma frase em inglês em que diz "alguns podem preferir um cantor brasileiro suave/mas eu desisto de todas as tentativas de perfeição", para reafirmar, conforme entrevista sua, a condição de que "sou brasileiro, sou casado e sou solteiro, sou baiano e estrangeiro..." Estrangeiro que, numa atitude de estranhamento, nos deixa ver a transformação do exótico em familiar e, particularmente, do familiar em exótico, através da operação de um "olhar antropológico". Trata-se de uma transformação relativizadora, próxima daquela realizada pelos antropólogos no trabalho de campo, sugerindo um processo ritual em que a dramatização ensaiada revela-se, simbolicamente, pela morte, liminaridade e ressurreição do estrangeiro, esse "outro" que habita em mim.

\section{“Outros", estrangeiros}

A modernidade introduziu, de modo significativo, a sensação de "estrangeiridade" no mundo urbano. Parafraseando Lofland, Mariz (1988, p. 87), diz que "ser um estranho é um fenômeno recente, que não era comum às sociedades tribais e antigas”. Sennet (1983), Benjamin (1994), Bauman (1998) e outros chamam a atenção para a cidade como um mundo de estranhos. Novos personagens entram em cena, tais como: os Apaches, os Zazous, os Boppers, os punks, os skinheads, os new agers e outros, muitos outros. Também os estranhos "estilos de vida" das classes operárias, oriundos do meio rural, iriam despertar muito cedo a curiosidade dos intelectuais de plantão, haja vista a literatura do século XIX, às voltas 
com o estranho mundo das "classes perigosas", tão bem dramatizado nos romances, contos e poemas de Charles Dickens, Emile Zola, Edgar Allan Poe e Charles Baudelaire. ${ }^{8}$

Mundo de estranhos, na cidade o indivíduo se torna um pouco flâneur ao mesmo tempo em que se torna comum a atitude blasé da qual fala Simmel em A metrópole e a vida mental (1973), isto é, a necessidade de um certo distanciamento para preservar sua integridade psicológica. O mesmo Simmel (1983) e Schutz (1977, 1979), eles mesmos estrangeiros, são os intelectuais que teorizam sobre o fenômeno social do estrangeiro, de um ponto de vista fenomenológico, acentuando o seu caráter de proximidade e distância. Apesar das dificuldades experimentadas pelo estrangeiro em suas relações de proximidade com o outro, Simmel e Schutz vêem nele a possibilidade de um olhar objetivo, resguardado pela distância social e cultural. Não estando o estrangeiro sentimentalmente envolvido com a "adoração dos ídolos das tribos" do lugar, ele consegue com maior objetividade enxergar as incoerências e inconsistências do mundo social do qual se aproxima. De resto diz Schutz (1977, p. 106), "a razão mais profunda da sua objetividade reside em sua própria experiência amarga dos limites do pensamento habitual”, que o leva a duvidar das representações naturalistas do mundo, isto é, o mundo visto como algo natural. A experiência do estrangeiro representa uma espécie de quebra ou suspensão (epoché) da realidade social e dos valores culturais.

Nos extremos, nenhum estrangeiro se compara ao estranho $O$ estrangeiro, de Camus. Mersault, a personagem estrangeira do romance de início nos lembra a atitude blasé de que fala Simmel, mas logo se vê que a ultrapassa. Mersault constitui-se um estrangeiro de si mesmo; um exílio interior o coloca tanto para além de seus compatriotas franceses quanto dos árabes, com quem convive na Argélia. Sua indiferença pela vida em geral o coloca muito próximo do niilismo que, segundo Nietzsche (1983, p. 379), representa "a radical recusa de valor, sentido e desejabilidade". O niilismo de Mersault não se deve somente ao fracasso da "crença nas categorias da razão" se pensarmos em Nietzsche, mas também em função do espírito de época a que pertence, ou seja, o período da Segunda Guerra Mundial. O vazio que habita Mersault será preenchido pela indiferença ao mundo e à humanidade. Momentos antes de ser 
executado, após refletir sobre o sentido da morte da mãe e da sua própria, chega à seguinte conclusão:

Como se esta grande cólera me tivesse limpo do mal, esvaziado da esperança, diante desta noite carregada de sinais e de estrelas, eu abria-me pela primeira vez à terna indiferença do mundo. Por o sentir tão parecido comigo, tão fraternal, senti que fora feliz e ainda o era. Para que tudo ficasse consumado, para que me sentisse menos só, faltava-me desejar que houvesse muito público no dia da minha execução e que os espectadores me recebessem com gritos de ódio. (CAmus, 1982, p. 298)

Em verdade, não é o estrangeiro o ser indiferente à humanidade, é a própria humanidade que é indiferente. Mas, para que não seja tratado com indiferença, Mersault deseja ser recebido com gritos de ódio; afinal, o ódio o torna real. O curioso é que a partir da morte da mãe, Mersault descobre e revela-se um estrangeiro, um órfão de país.

No entanto, desde Nietzsche passando por Mersault (e Camus) até o presente pós-moderno, cada vez mais o indivíduo busca conhecerse melhor ainda que sob o risco de perder-se no vazio de si mesmo. Assim, em um mundo pós-moderno em que, aparentemente, a globalização da economia e a mundialização da cultura parecem pôr fim às fronteiras reais e imaginárias entre as nações, entre os homens e as coisas, não são poucas as referências à crise das identidades e das relações de oposição entre o “eu” e o "outro". Quando o compositor Arnaldo Antunes (ex-integrante do grupo de rock Titãs), em entrevista a um jornal, afirma: "Não sou brasileiro nem sou estrangeiro", ele relativiza as fronteiras da identidade nacional. Ao afirmar-se nem brasileiro nem estrangeiro, Antunes não deixa de expressar o que é enquanto "sou". Em tempos pós-modernos, a representação da identidade como algo fixo e acabado cede lugar à idéia de pluralidade.

No mundo pós-moderno, o estranho e o estrangeiro já não são mais o "outro", enquanto o imigrante, o selvagem, o bárbaro, o desconhecido, o forasteiro, o turista, o inimigo e outros, mas também o "id" freudiano, os anjos, a nação, o idoso, a criança, as tribos urbanas, os "não-lugares" serão a própria cidade. A título de ilustração vale lembrar a temática do estrangeiro no cinema, tão recorrente em filmes como 
Bagdá Café e muitos outros. Do viajante clássico, passando pelos beatniks aos anjos de Win Wenders, o estrangeiro nos mostra quão habitantes de um cenário em ruínas estamos:

As ruínas são o lugar do estrangeiro. São o testemunho, vivido cotidianamente, da perda do mundo. O indivíduo fora do tempo, o sobrevivente, faz delas o seu lugar. Ele se reconhece nelas. A mistura de objetos quebrados e fragmentos arquitetônicos se parece muito com sua própria falta de unidade e história pessoal, são o espelho daquele que não tem rosto nem lugar. Refletem o seu vazio, sua confusão, seu deslocamento. (Регхото, 1988, p. 160)

Em suma, nem sempre o estranho está confinado ao mundo do "outro"; ao contrário, para Freud, o "outro", o estranho ou o estrangeiro, habita em nós. ${ }^{9}$ O outro é o meu próprio inconsciente. Daí, numa postura muito próxima à dos antropólogos, ele nos chama a atenção para o fato de que "nem tudo o que é novo e não familiar é assustador; a relação pode ser invertida" (Freud, 1976, p. 87). Também é o que nos parece querer dizer o antropólogo Marc Augé, para quem o estranho é

um mundo onde se nasce numa clínica e se morre num hospital, onde se multiplicam, em modalidades luxuosas ou desumanas, os pontos de trânsito e as ocupações provisórias (as cadeias de hotéis e os terrenos invadidos, os clubes de férias, os acampamentos de refugiados, as favelas destinadas aos desempregados ou à perenidade que apodrece), onde se desenvolve uma rede cerrada de meios de transportes que são também espaços habitados, onde o frequentador das grandes superfícies, das máquinas automáticas e dos cartões de crédito renovado com os gestos do comércio "em surdina", um mundo assim prometido à individualidade solitária, à passagem, ao provisório e ao efêmero, propõe ao antropólogo, como aos outros, um objeto novo cujas dimensões inéditas convém calcular antes de se perguntar a que olhar ele está sujeito. (Augé, 1994, p. 73-74)

Em suma, em uma época em que a globalização promete unificar o mundo, aproximando as distâncias, relativizando as fronteiras entre o local e o global, o estrangeiro assume um colorido especial na pós-modernidade na medida em que se torna símbolo de identidade cultural. 


\title{
Um ponto de vista
}

De resto, fica-nos a dúvida, lançada por Kristeva (1994, p. 22), "devemos admitir que nos tornamos estrangeiros num outro país porque já o somos por dentro?". Talvez, desde que se considere que o que "somos por dentro" é um ponto de vista produzido por um "olhar de fora". Mais do que uma simples visão de "dentro" ou de "fora", "interna" ou "externa" ao "ser" estrangeiro, o que está em jogo, na verdade, é uma "visão de mundo". Dependendo de onde e para onde se olha, certamente se vêem coisas diferentes; afinal, a maneira como se olha para as coisas ou como as coisas são vistas tem implicações epistemológicas e ontolólogicas sobre o estrangeiro.

O estrangeiro está no olho de quem vê e não naquilo que é visto. "Ser" estrangeiro implica uma mudança de olhar, mudança de perspectiva. É preciso comparar para poder relativizar e, assim, alcançar, quem sabe, uma visão mais profunda do mundo que nos cerca. Nesse sentido, a metáfora do "olhar antropológico" representa um ponto de partida importante para o trabalho de interpretação e compreensão desenvolvido pela antropologia no estudo dos "outros", suas culturas, costumes, hábitos etc., bem como na reflexão dos costumes, hábitos etc. da cultura do "eu".

Talvez não seja exagerado ver o antropólogo como uma espécie de estrangeiro. Isto porque não só os estudos de outras culturas muito diferentes da sua, exigindo um deslocamento espacial, conferem a ele a experiência do "olhar antropológico", mas, sobretudo, quanto à necessidade de estranhar, transformar-se em estrangeiro, ainda que temporariamente, quando se trata de estudar a sua própria cultura ou grupos muito próximos. É com um olhar, orientado não só para o "outro", mas também para o que está próximo e familiar e, portanto, não necessariamente conhecido, é que, inicialmente, podemos ver na antropologia uma "ciência do olhar", cujo objeto de estudo privilegiado são "os pontos de vistas nativos".

\begin{abstract}
Before being a juridical fact, linguistic or political, the foreign is a narrative about the difference built by the look, whose main attribute is to show
\end{abstract}


a system of social meanings. The song $O$ estrangeiro, by Caetano Veloso, proposes an exercise of reflexion leaded by an "anthropological look", it is to say by a transformation process of the familiar into exotic and of the exotic into familiar, about the meaning of the foreign in the postmodern context.

Key words: Foreign, anthropological look, postmodern context.

\section{Notas}

1. A etnopoesia situa-se a meio caminho entre a antropologia e a literatura. Um texto musical não se confunde exatamente com uma etnografia, mas pode ser utilizado com bastante proveito pela antropologia da literatura como sugere DaMatta (1993).

2. Por definição o estrangeiro é o "outro", é o que seduz e ameaça, podendo gerar tanto experiências de xenofobismo quanto de exotismo. Assumindo significados diferentes no tempo e no espaço, o estrangeiro tem provocado a reflexão de antropólogos, sociólogos, historiadores e filósofos, adquirindo o status de um verdadeiro problema ontológico na medida em que envolve a produção de conhecimento e a subjetividade.

3. À primeira vista pode-se sugerir uma visão etnocêntrica de Canevacci, assim como o exotismo analisado por Said (1990) representa uma invenção do "eu" ocidental.

4. Não se pode aqui deixar de fazer, por mínima que seja, referência à importância do olhar na cultura ocidental. Do mito da caverna, de Platão, ao Panopthicon, de Bentham, passando pelo flâneur às tecnologias virtuais, o olhar tornou-se uma das expressões mais bem acabadas que ilustram a produção do conhecimento e da construção da realidade social no mundo moderno, e, por isso mesmo, também serve de metáfora "natural" para as visões etnocênctricas.

5. A verdade é que nem sempre nos damos conta da "realidade", pois a visão de mundo como algo natural embaça as vistas de nós mesmos e de nosso mundo. Segundo Nadel (1987, p. 55), "viver com um povo não significa uma garantia de que se vai descobrir todos os fatos relevantes a seu respeito. Se este fosse o caso, seríamos todos sociólogos, especializados em nossa própria sociedade".

6. No impressionismo, a pintura é uma realidade apreendida pelo olhar. Duarte (1993, p. 254), comentando a pintura impressionista de Seurat, diz que "para Seurat, o real é a própria pintura".

7. Resumidamente, o conto de Hans Christian Andersen, "A roupa nova do rei", fala de um rei vaidoso que manda confeccionar uma bela roupa e, para tanto, contrata um alfaiate que diz que somente os sábios e os inteligentes têm a capacidade de vê-la, pois trata-se de uma roupa invisível. No dia marcado para mostrar sua bela roupa, o rei aparece nu diante dos súditos, mas uma criança ousa dizer que o rei está nu. Moral da história: é preciso ousar olhar o diferente naquilo que todos vêem o igual.

8. É bem verdade que o problema do estrangeiro não se reduz aos campos das cidades e da literatura. O estrangeiro exerce um papel fundamental na constituição da ordem 
social burguesa moderna, sobretudo, na construção dos Estados Nacionais. Para uma análise do "sentimento de estrangeiridade" experimentado no processo de construção da identidade nacional brasileira durante a belle époque, ver Rocha (2001).

9. Paralelamente às descobertas de Freud, o mundo se viu povoado de "outros" na forma de estranhos "monstros" habitando os homens, haja vista a literatura de horror produzida na segunda metade do século XIX.

\section{Referências}

Augé, Marc. Não-lugares: introdução a uma antropologia da supermodernidade. Campinas: Papirus, 1994.

Bauman, Zygmunt. O mal-estar da pós-modernidade. Rio de Janeiro: Zahar, 1998.

Benjamin, Walter. Charles Baudelaire: um lírico no auge do capitalismo. São Paulo: Brasiliense, 1994. (Obras Escolhidas III).

Caetano Veloso. O estrangeiro. [Rio de Janeiro]: Polygram, 1989.

CAmus, Albert. Estado de sítio: o estrangeiro. São Paulo: Abril Cultural, 1982.

Canevacci, Massimo. Sincretismos: uma exploração das hibridações culturais. São Paulo: Studio Nobel, 1996.

Carvalho, Neuza C. O estranhamento estrangeiro de Caetano Veloso. Miscelânia. Assis, v. 1, 1993.

DaMatta, Roberto. Ensaios de antropologia estrutural. Petrópolis: Vozes, 1973.

. O ofício de etnólogo, ou como ter "Anthropological blues". In:

Nunes, Edson O. (Org.). A aventura sociológica: objetividade, paixão, improviso e método na pesquisa social. Rio de Janeiro: Zahar, 1978.

- Conta de mentiroso: sete ensaios de antropologia brasileira. Rio de Janeiro: Rocco, 1993.

Duarte, Paulo Sérgio. O que Seurat será?. In: Novaes, Adauto. (Org.). O olhar. São Paulo: Companhia das Letras, 1988.

FICHTE, Hubert. Etnopoesia: antropologia poética das religiões afroamericanas. São Paulo: Brasiliense, 1987. 
Freud, Sigmund. O estranho. In: Uma criança é espancada: sobre o ensino da psicanálise nas universidades e outros trabalhos. Rio de Janeiro: Imago, 1976.

KRISTEVA, Julia. Estrangeiros para nós mesmos. Rio de Janeiro: Rocco, 1994.

LÉvi-STrauss, Claude. Tristes trópicos. Lisboa: Edições 70, 1979.

Luchesi, Ivo; Dieguez, Gilda K. Caetano, por que não?: uma viagem entre a aurora e a sombra. Rio de Janeiro: Leviatã, 1993.

Mariz, Cecília L. O estrangeiro e o homem moderno. Cadernos de Estudos Sociais, Recife, v. 4, n. 1, 1988.

Nadel, S. F. Compreendemos os povos primitivos. In: Feldman-Bianco, Bela (Org.). Antropologia das sociedades contemporâneas: métodos. São Paulo: Global, 1987.

NiETzSChe, Friedrich. Obras incompletas. São Paulo: Abril Cultural, 1983.

Peixoto, Nelson Brissac. Cenários em ruínas: a realidade imaginária contemporânea. São Paulo: Brasiliense, 1988.

Rocha, Gilmar. Nação, tristeza e exotismo no Brasil da belle époque. Varia história. Belo Horizonte, v. 24, 2001. [No prelo].

Rugendas, Johann Moritz. Viagem pitoresca através do Brasil. Belo Horizonte: Itatiaia, 1989.

SAID, Edward W. Orientalismo: o Oriente como invenção do Ocidente. São Paulo: Companhia das Letras, 1996.

Schutz, Alfred. El problema de la realidade social. Buenos Aires: Amorrotu, 1977.

. Fenomenologia e relações sociais. Rio de Janeiro: Zahar, 1979.

SENNET, Richard. O declínio do homem público: as tiranias da intimidade. São Paulo: Companhia das Letras, 1993.

Simmel, Georg. A metrópole e a vida mental. In: Velho, Otávio (Org.). O fenômeno urbano. Rio de Janeiro: Zahar, 1973.

. Simmel: sociologia. In: Moraes Filho, Evaristo (Org.). São Paulo: Ática, 1983. 
Velho, Gilberto. Observando o familiar. In: Nunes, Edson O. (Org.). A aventura sociológica: objetividade, paixão, improviso e método na pesquisa social. Rio de Janeiro: Zahar, 1978. 

$\underline{\text { Resenhas }}$ 
